\title{
Bronchiolar Adenoma Transforming to Invasive Mucinous Adenocarcinoma: A Case Report
}

This article was published in the following Dove Press journal: OncoTargets and Therapy

\author{
Xu $\operatorname{Han}\left(\mathbb{D}^{1, *}\right.$ \\ Jialin $\mathrm{Hao}^{2, *}$ \\ Suling Ding ${ }^{3}$ \\ En-Hua Wang' \\ Liang Wang $\mathbb{D}^{\prime}$
}

'Department of Pathology, First Affiliated Hospital and College of Basic Medical Sciences, China Medical University, Shenyang, People's Republic of China; ${ }^{2}$ Key Laboratory of Medical Cell Biology, Ministry of Education, China Medical University, Shenyang, People's Republic of China; ${ }^{3}$ Department of Pathology, Jinzhou Central Hospital, Jinzhou, People's

Republic of China

*These authors contributed equally to this work
Correspondence: Liang Wang Department of Pathology, First Affiliated Hospital and College and Basic Medical Sciences, China Medical University, Shenyang, People's Republic of China $\mathrm{Tel} / \mathrm{Fax}+862423261638$

Email cmuwangliang@qq.com

\begin{abstract}
Bronchiolar adenoma (BA) is recognized as a neoplasm with benign clinical course. Histologically, BA is characterized by nodular proliferation of the bilayered bronchiolar-type epithelium, including multipartite epithelial cells and a continuous layer of basal cells. Recent reports have revealed the frequent presence of driver gene mutations in BA, suggesting its neoplastic nature. However, it is still debatable whether BA has malignant potential. Herein, we report the first case of BA harboring the same KRAS mutation with the adjacent invasive mucinous adenocarcinoma (IMA). Additionally, the loss of continuity of the basal cell layer in the junctional zone between BA and IMA indicated a malignant transformation from BA to IMA in this particular case.
\end{abstract}

Keywords: bronchiolar adenoma, invasive mucinous adenocarcinoma, KRAS, transformation

\section{Introduction}

Bronchiolar adenoma (BA) is a newly designated rare entity by Chang et al in 2018, including the currently established ciliated muconodular papillary tumor (CMPT) and the so-called non-classic CMPT. ${ }^{1}$ Commonly, BAs present as discrete, sharply circumscribed lesions with a median size of $0.5 \mathrm{~cm}(0.2$ to $2 \mathrm{~cm}) .^{1-4}$ The most prominent histological feature of BA is the bilayered cell structures composed of the continuous basal cell layer (p40 and CK5/6-positive), and the surface cell layer consists of different proportions of mucinous cells, ciliated cells, Clara cells and type II pneumocytes. The composition of the surface epithelium renders BA with subtypes, including proximal-type and distal-type. The primary differential diagnosis for proximal-type BA with prominent mucinous feature is invasive mucinous adenocarcinoma (IMA). ${ }^{1}$ To date, no convincing evidence has been found on whether BA can transform to IMA. ${ }^{1-8}$ Herein, we report the pathological observation and molecular study of a special BA, which may shed new light on this point.

\section{Case Presentation}

A 70-year-old man with thirty years of smoking history presented with complaints of shortness of breath. Computed Tomography (CT) revealed a $1.5 \mathrm{~cm} \times 1.4 \mathrm{~cm}$ nodule in the middle lobe of the right lung. The lesion was lobulated, with spicule formation, associated with distal airway tracts (Figure 1A, red arrow). After excluding extrapulmonary metastases by imageology, lobectomy was performed. Gross examination revealed a demarcated, gray-white mucoid mass in the peripheral lung. No necrosis, hemorrhage or pleural indentation was noticed. 

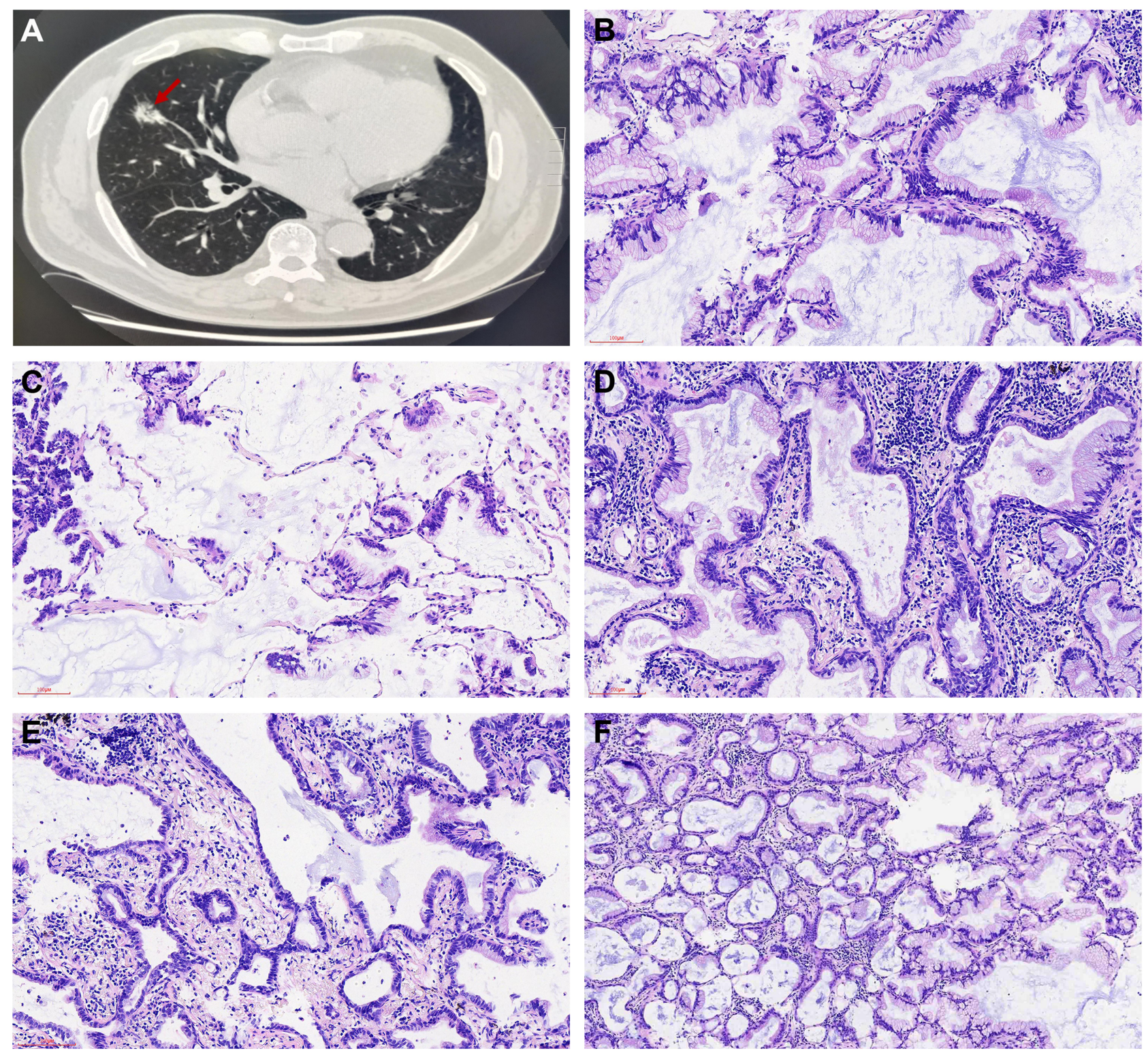

Figure I CT showed a $1.5 \mathrm{~cm} \times 1.4 \mathrm{~cm}$ mass in the middle lobe of the right lung, closely related to the bronchi (A, red arrow). The tumor is mainly composed of lepidicgrowing mucinous cells with papillary structures and abundant intra-alveolar mucus (B, 200x). The skipping growth pattern of tumor cells can be noticed (C, 200x). In certain glandular areas, the presence of basal cell layers could not be ruled out (D, 200x). A mixture of ciliated cells and columnar cells could be observed in the glandular area $(E, 200 \times)$. No distinct boundary was found in the junctional zone between the glandular and the lepidic areas (F, 100x).

Microscopically, the tumor was mainly composed of two patterns: glands lined with proliferative mucinous cells and tall columnar mucinous cells growing along the alveolar wall (Figure 1B). Papillary, micropapillary structures and intra-alveolar mucus can be seen. Based on the skipping growth pattern seen in certain areas (Figure 1C), the intraoperative pathological diagnosis favored IMA.

Postoperative pathological examination showed that, in some regions of glands, especially the center of the tumor, the presence of basal layers could not be ruled out. The luminal layers of the glands were lined predominantly by cuboidal cells, interpreted by ciliated cells and columnar cells (Figure 1D). Intraluminal papillaries composed of mucinous cells could be noted in certain glands. (Figure 1E). No distinct boundary was found between the glandular and the lepidic areas (Figure 1F). Hence, immunohistochemistry was performed with a panel including CK7, TTF-1, Napsin A, CK5/6, p63, p40, and Ki-67. The expression of p40, p63, and CK5/6 demonstrated an area composed of continuous basal layer measuring $5 \times 3 \mathrm{~mm}^{2}$ (Figure $2 \mathrm{~A}$ and B). TTF-1 was positive in the columnar and cuboidal cells in the luminal layer of the glands (Figure 2C, red arrows). 
Interestingly, in the adjunct lepidic areas, basal cells were absent, as demonstrated by the negative staining of basal markers (Figure 2D-F, black arrows). In the junctional zone, p63, p40, and CK5/6 showed only sporadic expression (Figure 2D-F, purple arrows). The Ki-67 index was similar among the two areas (1\%).

Furthermore, these two distinct areas were microdissected and analyzed by a panel covering $E G F R, A L K$, ROS1, KRAS, NRAS, PIK3, HER2, and BRAF (Supplementary Figure 1). The same KRAS mutations (G12V) in both portions were identified (Figure 3), supporting
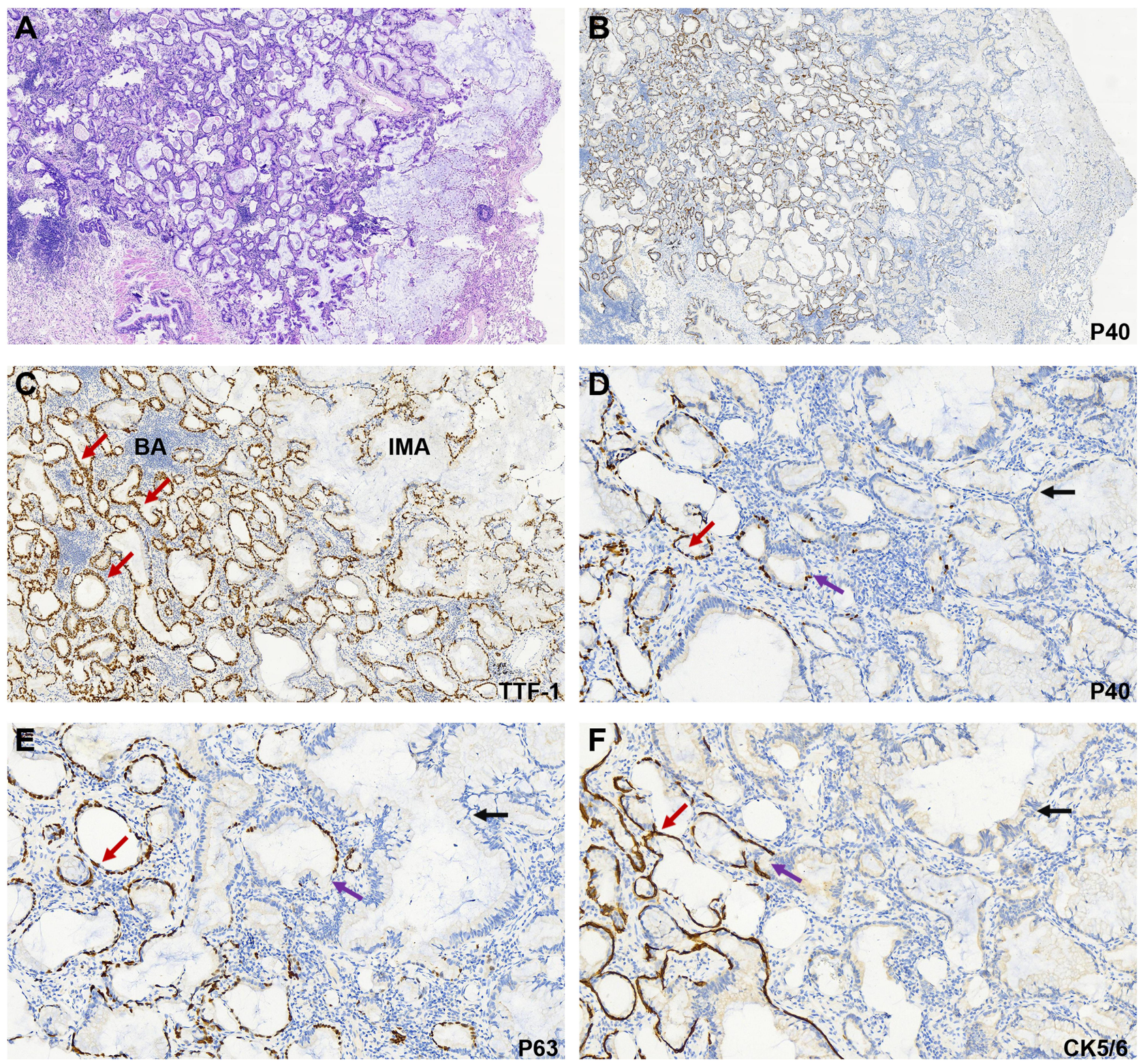

Figure 2 Hematoxylin-eosin ( $\mathrm{HE})$ and P40 stain of the glandular area with continuous basal layer, an area of $5 \times 3$ mm ${ }^{2}$ was demonstrated $(\mathbf{A}$ and $\mathbf{B}, 40 \times)$. The cuboidal and columnar cells in the luminal layer were TTF-I positive (red arrows; C, I00x). Loss of continuity of the basal cell layers at the BA to IMA junctional zone: red arrows indicate the continuous basal cell layer; purple arrows indicate the sporadic staining of basal cell marker in the junctional area; black arrows indicate the absence of basal cell layer (D-F, 200x). 

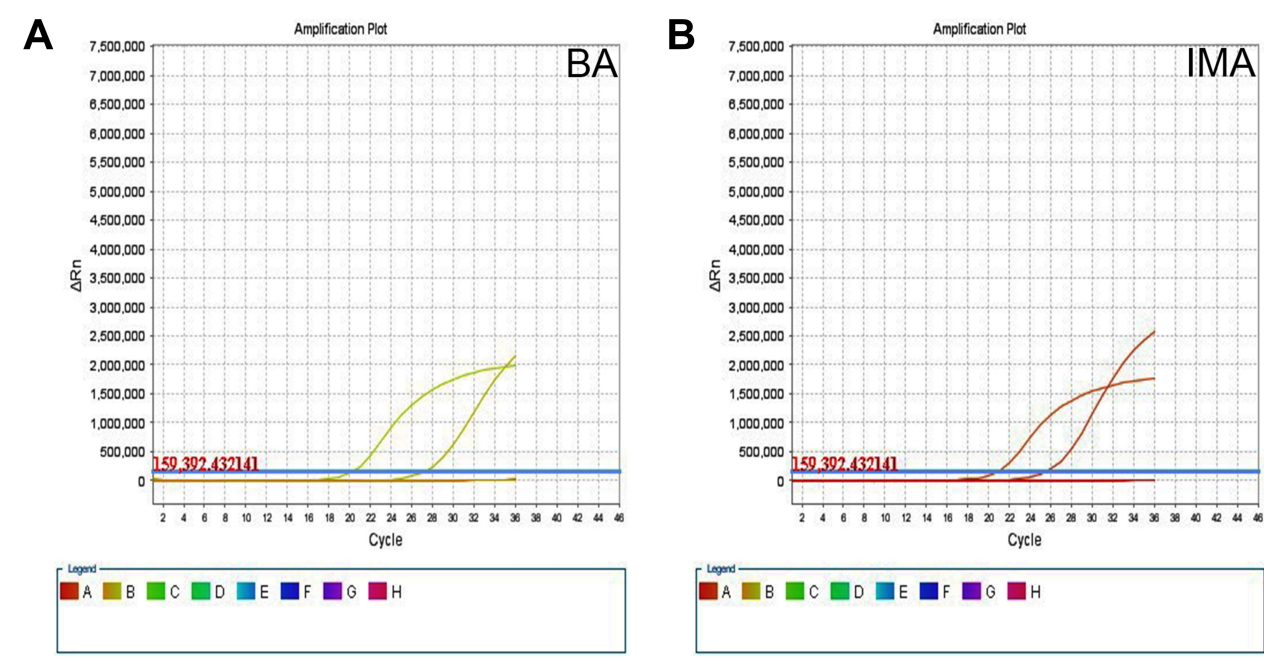

Figure 3 Quantitative reverse-transcript polymerase chain reaction (qRT-PCR) revealed the same KRAS mutations (GI2V) in both BA (A) and IMA (B).

the histological commonalities, it is difficult to discriminate between the proximal-type BA and IMA without the assistance of immunohistochemistry (IHC). Recognition of a continuous basal cell layer is the key to distinguish these lesions, which can be confirmed by IHC with basal cell markers (p40, p63, and CK5/6) following morphological suspicion. Additionally, the presence of ciliated cells (Figure 1D) would also support the diagnosis of BA in this case.

According to Chang et al, BAs exhibit a morphologic spectrum reflecting either proximal or distal bronchiolar differentiation, with cases showing overlaps. ${ }^{1}$ Zheng et al found similar immunophenotypes among classic and non-classic ciliated muconodular papillary tumor (CMPT), including tripartite differentiation of the epithelium. ${ }^{4}$ In this case, the epithelium is lined predominantly by terminal respiratory epithelial cells (TTF-1 expression shown in Figure 2C; diffuse CK7 and focal Napsin A expression are not shown), along with the presence of ciliated cells and abundant mucinous cells. Several markers for mucinous cells are usually positive in CMPTs, including $\mathrm{HNF}_{\alpha} \alpha{ }^{8}$ MUC1, and MUC5AC. ${ }^{5,9,10}$ HNF $4 \alpha$ is highly sensitive for identifying neoplastic mucinous epithelial cells. ${ }^{11}$ However, its reliability and specificity are questioned because diverse percentages of expression were reported in different papers (ranging from $11 \%{ }^{12}$ to $92 \%{ }^{11}$ ). Besides, Udo et al found HNF $4 \alpha$ positivity in four cases of CMPTs. ${ }^{8}$ Additional studies are still needed to validate the positivity of diverse immunomarkers in CMPTs.
Peribronchiolar metaplasia (PBM) is a reactive extension of bronchiolar-type epithelium along the peribronchiolar alveolar walls. ${ }^{13}$ Usually, PBM demonstrates as small (diameter $<1 \mathrm{~mm}$ ) and multifocal lesions. ${ }^{14}$ Histologically, PBM can resemble atypical adenomatous hyperplasia (AAH) or CMPT, but immunohistochemically, the proliferating epithelia in PBM are usually TTF-1 negative. ${ }^{15}$ In the current case, the larger size of the glandular area $\left(5 \times 3 \mathrm{~mm}^{2}\right)$, the positive TTF-1 staining and the mixed cellularity in the luminal layer favored the diagnosis of bronchiolar adenoma.

The genomic profile of BA is considered unique and distinct from lung adenocarcinomas. However, several BA cases have been reported for harboring mutations of common driver genes for lung adenocarcinoma, such as KRAS, BRAF, and $E G F R .^{6-8}$ A relatively high percentage (50\%) of $B R A F$ mutation was found in BA despite its benign clinical course. ${ }^{6}$ Hence, $B R A F$ mutation in BA merely represents evidence for a neoplastic process and is not synonymous with malignancy. Additionally, it should be noted that the KRAS mutation can be detected in $80 \%$ of IMA. ${ }^{16}$ Meanwhile, $24 \%$ of BA have been reported to bear KRAS mutation. ${ }^{1}$ Interestingly, the missense mutation in the KRAS gene is characteristic of tobacco-related carcinogenic signature, ${ }^{17}$ this might explain why the current case showed malignant transformation.

To conclude, in the current case, the transition of the basal cells from presence to absence, the discontinuing of the basal cell layer in the junctional zone, and the same genetic mutations all suggest a malignant transformation from BA to IMA. This case also highlights the importance of complete excision of BA with adequate margins, as it might be a preinvasive lesion of IMA. 


\section{Data Sharing Statement}

The datasets supporting the conclusions of this case are included within the article.

\section{Ethical Approval and Consent to Participate}

Ethical approval for this study was obtained from the First Affiliated Hospital of China Medical University's institutional ethics review boards. Writing consent to participate was provided by the patients for the present research.

\section{Patient Consent for Publication}

Informed consent was obtained from the patients for the publication of cases and any accompanying images. Copies of the written consent are available for review by the Editor-in-Chief of this journal.

\section{Author Contributions}

All authors made a significant contribution to the work reported, whether that is in the conception, study design, execution, acquisition of data, analysis and interpretation, or in all these areas; took part in drafting, revising or critically reviewing the article; gave final approval of the version to be published; have agreed on the journal to which the article has been submitted; and agree to be accountable for all aspects of the work.

\section{Funding}

This study was supported by grants from Liaoning Technology Research Fund for Social Development and Industrialization to Liang Wang (2017225010).

\section{Disclosure}

The authors declare that they have no competing interests.

\section{References}

1. Chang JC, Montecalvo J, Borsu L, et al. Expansion of the concept of ciliated muconodular papillary tumors with proposal for revised terminology based on morphologic, immunophenotypic, and genomic analysis of 25 cases. Am J Surg Pathol. 2018;42(8):1010-1026. doi:10.1097/PAS.0000000000001086

2. Chuang H-W, Liao J-B, Chang H-C, Wang J-S, Lin S-L, Hsieh -P-P. Ciliated muconodular papillary tumor of the lung: a newly defined peripheral pulmonary tumor with conspicuous mucin pool mimicking colloid adenocarcinoma: a case report and review of literature. Pathol Int. 2014;64(7):352-357. doi:10.1111/pin.12179
3. Shao K, Wang Y, Xue Q, et al. Clinicopathological features and prognosis of ciliated muconodular papillary tumor. J Cardiothorac Surg. 2019;14(1). doi:10.1186/s13019-019-0962-3.

4. Zheng Q, Luo R, Jin Y, et al. So-called "non-classic" ciliated muconodular papillary tumors: a comprehensive comparison of the clinicopathological and molecular features with classic ciliated muconodular papillary tumors. Hum Pathol. 2018;82:193-201. doi:10.1016/j.humpath.2018.07.029

5. Kamata T, Yoshida A, Kosuge T, Watanabe S-I, Asamura H, Tsuta K Ciliated muconodular papillary tumors of the lung: a clinicopathologic analysis of 10 cases. Am J Surg Pathol. 2015;39 (6):753-760. doi:10.1097/PAS.0000000000000414

6. Kamata T, Sunami K, Yoshida A, et al. Frequent BRAF or EGFR mutations in ciliated muconodular papillary tumors of the lung. J Thorac Oncol. 2016;11(2):261-265. doi:10.1016/j.jtho.2015.10.021

7. Liu L, Aesif SW, Kipp BR, et al. Muconodular papillary tumors of the lung can occur in western patients and show mutations in BRAF and AKT1. Am J Surg Pathol. 2016;40(12):1631-1636. doi:10.1097/ PAS.0000000000000707

8. Udo E, Furusato B, Sakai K, et al. Ciliated muconodular papillary tumors of the lung with KRAS/BRAF/AKT1 mutation. Diagn Pathol. 2017;12(1). doi:10.1186/s13000-017-0651-2.

9. Sato S, Koike T, Homma K, Yokoyama A. Ciliated muconodular papillary tumour of the lung: a newly defined low-grade malignant tumour. Interact Cardiovasc Thorac Surg. 2010;11(5):685-687. doi:10.1510/icvts.2009.229989

10. Kon T, Baba Y, Fukai I, Watanabe G, Uchiyama T, Murata T. Ciliated muconodular papillary tumor of the lung: a report of five cases. Pathol Int. 2016;66(11):633-639. doi:10.1111/pin.12460

11. Sugano M, Nagasaka T, Sasaki E, et al. HNF4a as a marker for invasive mucinous adenocarcinoma of the lung. Am J Surg Pathol. 2013;37(2):211-218. doi:10.1097/PAS.0b013e31826be303

12. Kriegsmann M, Harms A, Longuespée R, et al. Role of conventional immunomarkers, HNF4- $\alpha$ and SATB2, in the differential diagnosis of pulmonary and colorectal adenocarcinomas. Histopathology. 2018;72 (6):997-1006. doi:10.1111/his.13455

13. Fukuoka J, Franks TJ, Colby TV, et al. Peribronchiolar Metaplasia A common histologic lesion in diffuse lung disease and a rare cause of interstitial lung disease. Am J Surg Pathol. 2005;29(7):948-954. doi:10.1097/01.pas.0000168177.71405.ac

14. Wang H, Lin D-L, Hu Y-J. Solitary peribronchiolar metaplasia and bronchiolar adenoma: do they represent an equal entity? Gen Thorac Cardiovasc Surg. 2019;68(2):204-205. doi:10.1007/s11748-019-01224-1

15. Yasuura Y, Kayata H, Mizuno K, et al. Solitary peribronchiolar metaplasia showing a sub-solid nodule on computed tomography. Gen Thorac Cardiovasc Surg. 2019;67(12):1093-1096. doi:10.1007/ s11748-019-01089-4

16. Nakaoku T, Tsuta K, Ichikawa H, et al. Druggable oncogene fusions in invasive mucinous lung adenocarcinoma. Clin Cancer Res. 2014;20(12):3087-3093. doi:10.1158/1078-0432.CCR-14-0107

17. Sun S, Schiller JH, Gazdar AF. Lung cancer in never smokers a different disease. Nat Rev Cancer. 2007;7(10):778-790. doi:10.1038/ $\operatorname{nrc} 2190$ 


\section{Publish your work in this journal}

OncoTargets and Therapy is an international, peer-reviewed, open access journal focusing on the pathological basis of all cancers, potential targets for therapy and treatment protocols employed to improve the management of cancer patients. The journal also focuses on the impact of management programs and new therapeutic agents and protocols on patient perspectives such as quality of life, adherence and satisfaction. The manuscript management system is completely online and includes a very quick and fair peer-review system, which is all easy to use. Visit http://www.dovepress.com/ testimonials.php to read real quotes from published authors.

Submit your manuscript here: https://www.dovepress.com/oncotargets-and-therapy-journal 